\title{
Community health workers impact on maternal and child health outcomes in rural South Africa - a non-randomized two- group comparison study
}

Karl W. le Roux ${ }^{1,2,3,4}$, Ellen Almirol ${ }^{5}$, Panteha Hayati Rezvan ${ }^{5}$, Ingrid M. le Roux ${ }^{6}$, Nokwanele Mbewu' Elaine Dippenaar ${ }^{1}$, Linnea Stansert-Katzen ${ }^{1,2}$, Venetia Baker ${ }^{2}$, Mark Tomlinson ${ }^{1,7+}$ and M. J. Rotheram-Borus ${ }^{5^{*+}}$ (D)

\begin{abstract}
Background: Home visits by paraprofessional community health workers (CHWs) has been shown to improve maternal and child health outcomes in research studies in many countries. Yet, when these are scaled or replicated, efficacy disappears. An effective CHW home visiting program in peri-urban Cape Town found maternal and child health benefits over the 5 years point but this study examines if these benefits occur in deeply rural communities.

Methods: A non-randomized, two-group comparison study evaluated the impact of CHW in the rural Eastern Cape from August 2014 to May 2017, with 1310 mother-infant pairs recruited in pregnancy and 89\% were reassessed at 6 months post-birth.

Results: Home visiting had limited, but important effects on child health, maternal wellbeing and health behaviors. Mothers reported fewer depressive symptoms, attended more antenatal visits and had better baby-feeding practices. Intervention mothers were significantly more likely to exclusively breastfeed for 6 months (OR: 1.8; 95\% Cl: $1.1,2.9)$, had lower odds of mixing formula with baby porridge (regarded as detrimental) (OR: $0.4 ; 95 \%$ Cl: $0.2,0.8$ ) and were less likely to consult traditional healers. Mothers living with HIV were more adherent with co-trimoxazole prophylaxis $(p<0.01)$. Intervention-group children were significantly less likely to be wasted (OR: $0.5 ; 95 \% \mathrm{Cl} 0.3-0.9)$ and had significantly fewer symptoms of common childhood illnesses in the preceding two weeks (OR: 0.8; $95 \%$ Cl: $0.7,0.9)$.
\end{abstract}

Conclusion: The impact of CHWs in a rural area was less pronounced than in peri-urban areas. CHWs are likely to need enhanced support and supervision in the challenging rural context.

Keywords: Community health workers, Rural, Eastern cape, South Africa, Wasting, Depression

\footnotetext{
* Correspondence: cchpublications@mednet.ucla.edu

${ }^{\dagger}$ Mark Tomlinson and MJ Rotheram-Borus are Joint senior authors

${ }^{5}$ Department of Psychiatry and Biobehavioral Sciences, Semel Institute,

University of California, 10920 Wilshire Boulevard, Suite 350, Los Angeles, CA 90024-6521, USA

Full list of author information is available at the end of the article
}

(c) The Author(s). 2020 Open Access This article is licensed under a Creative Commons Attribution 4.0 International License, which permits use, sharing, adaptation, distribution and reproduction in any medium or format, as long as you give appropriate credit to the original author(s) and the source, provide a link to the Creative Commons licence, and indicate if changes were made. The images or other third party material in this article are included in the article's Creative Commons licence, unless indicated otherwise in a credit line to the material. If material is not included in the article's Creative Commons licence and your intended use is not permitted by statutory regulation or exceeds the permitted use, you will need to obtain permission directly from the copyright holder. To view a copy of this licence, visit http://creativecommons.org/licenses/by/4.0/ The Creative Commons Public Domain Dedication waiver (http://creativecommons.org/publicdomain/zero/1.0/) applies to the data made available in this article, unless otherwise stated in a credit line to the data. 


\section{Background}

Rural populations face greater challenges than their urban counterparts in accessing good quality health care. Not only are health facilities in rural areas less accessible due to distance and topography, but clinics and hospitals are often under-resourced, poorly maintained [1,2] and lack essential medicines [3]. Furthermore, there may be a scarcity of trained and skilled healthcare workers in rural areas, including doctors, pharmacists and nurses leading to suboptimal health outcomes [2, 4].

One proposed remedy to the shortage of human resources is training and employing lay healthcare workers, usually known as village or community healthcare workers (CHWs). CHWs are typically community members who are trusted and respected, and able to provide a link between people's homes and formal government primary health care (PHC) clinics [5]. The efficacy of CHWs in reducing the burden of care in understaffed and under-resourced health systems remains a point of debate, with their perceived value varying significantly $[6,7]$.

In 2011, the South African (SA) National Department of Health (NDOH) launched 'The Re-engineering of Primary Health Care' policy, which relies heavily on CHWs, to reduce maternal and child mortality and improve access to health care [8-11]. Successful CHW programs have provided services to over 200 million people over the past 2 decades in Brazil, Bangladesh and Nepal [12]. CHWs have implemented preventive interventions for maternal and child health [13-15]. CHW programs have been shown to reduce child mortality $[16,17]$, reduce maternal depression $[18,19]$, improve access to health care [7] and improve child growth and development [18-20]. Despite good evidence that well-managed $\mathrm{CHW}$ programs can positively influence a range of health outcomes, programs often face a myriad of practical obstacles that impact their effectiveness, particularly when expanded and replicated, and most $\mathrm{CHW}$ programs have not been able to be taken to scale whilst retaining effectiveness [21].

There has, therefore, been a call for more research on how to best implement $\mathrm{CHW}$ programs. This study builds on a series of evaluations of the Philani CHW program in Khayelitsha, Cape Town, which has shown long term benefits for maternal and child health outcomes [18, 19, 22-24]. This paper evaluates whether the CHW home-visiting model is equally effective in a deeply rural area where health providers and patients face many additional challenges in seeking and consistently receiving care.

\section{Methods}

\section{Setting}

The study was initiated in the rural Eastern Cape, in the catchment area of four clinics referring to Zithulele
District Hospital, situated in the King Sabata Dalidyebo Subdistrict of the OR Tambo district, one of the poorest municipalities in South Africa [25]. The catchment population is approximately 40,000, with a density of (124 people $/ \mathrm{km}^{2}$ ) [26] and the topography is hilly with deep river valleys and gorges. This, combined with poor road infrastructure, makes access to healthcare services challenging for much of the population.

\section{Study design}

This study was an early Phase II non-randomized twogroup comparison study evaluating the Philani HomeVisiting Model in the rural Eastern Cape of South Africa, called the Zithulele Mothers-to-be Assessment (ZiMBA). Recruitment started in August 2014 and ended in May 2017. Mothers were assigned based on the location of clinic: (1) Mapuzi and Tshezi, an area with home visiting by CHWs, which we will refer to as the "intervention" group or (2) Wilo and Luthubeni, areas with standard clinical care and no CHWs, as the "comparison" group. Philani CHWs focusing on maternal and child health, had been assigned to conduct home visits within designated geographical areas (i.e. intervention areas a year previously). The comparison area was matched with the intervention area based on clinic coverage, size, and distance from the district hospital by tar road, and a similar number of expected pregnancies, which was estimated from data of the Zithulele Births Follow-up Study (ZiBFUS) [27]. We ensured that a buffer zone existed between the two areas to avoid "cross-contamination" of intervention effects. See map Fig. 1.

\section{Intervention group}

Philani Maternal, Child Health and Nutrition Trust is a Non-Governmental Organization (NGO) that has been operating in peri-urban townships of Cape Town since 1979. Philani Mentor Mothers (Community Health Workers) are positive-deviant women whose children are thriving despite living in poverty [9]. These mothers are recruited to work in the areas where they live and are primarily trained to address maternal and child health issues in their communities at the level of the household. They perform regular house-to-house visits in their designated neighborhoods and identify both pregnant mothers and malnourished children who are then offered to entry into the program and followed up with regular home visits. The Community Health Workers (CHWs) build strong relationships with their clients and encourage mothers to attend antenatal care, immunize their children, weigh them regularly and breastfeed exclusively for 6 months; they advise mothers about health-care regimes, mental-health issues, antenatal care, optimal 


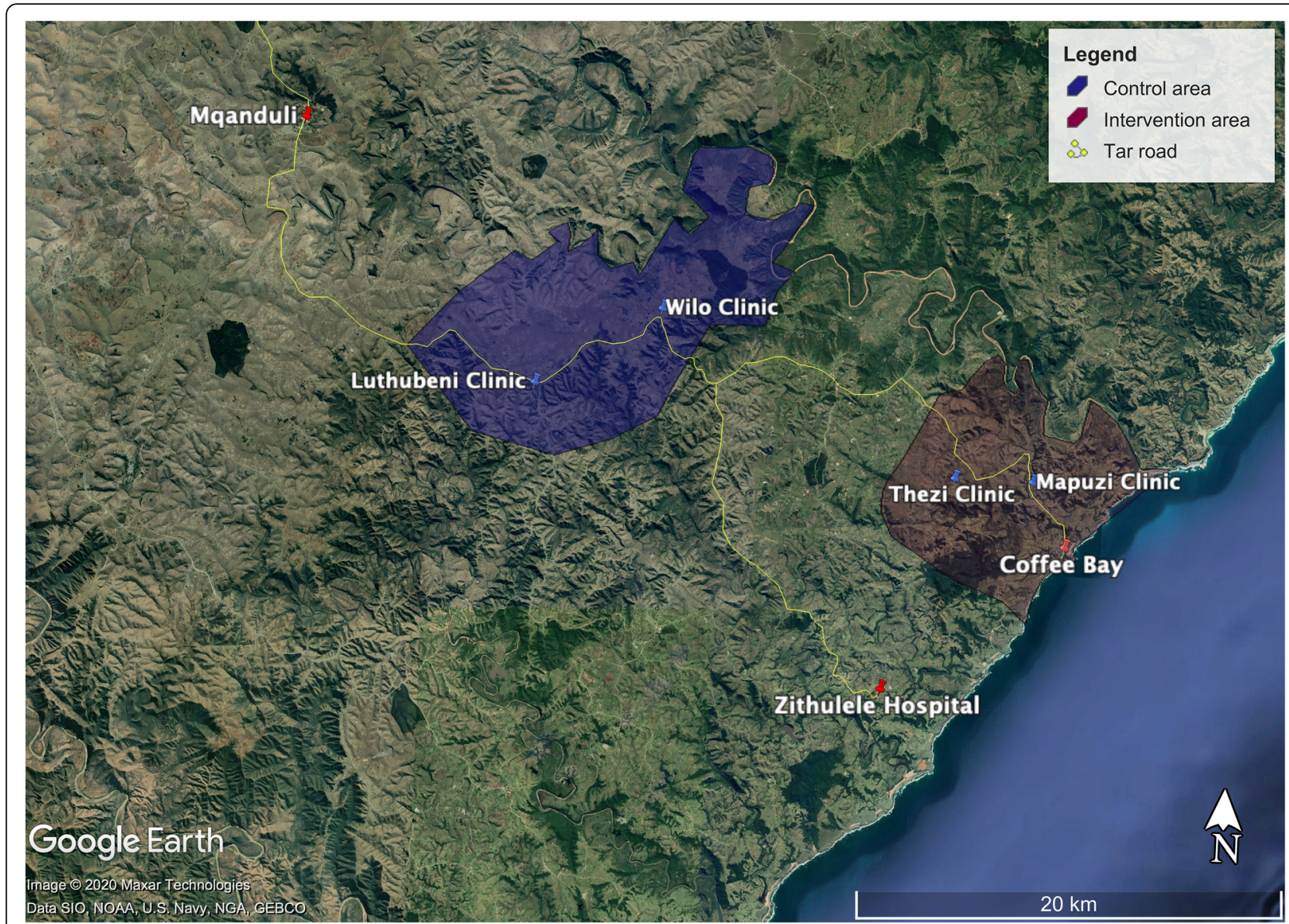

Fig. 1 Control and intervention areas, Eastern Cape, South Africa

infant feeding, accessing grants and accessing prevention of mother-to-child HIV transmission (PMTCT) [22]. CHW are also trained to identify and refer household members with possible $\mathrm{TB}$ and to support people living with HIV. A critical aspect of the intervention is the peer support provided to mothers who are struggling by women from their own community, who have faced similar challenges.

In 2010, the program was expanded to a deeply rural area around Zithulele District Hospital, and by 2013 to the Coffee Bay area - both in the OR Tambo district of the Eastern Cape. The CHW program was integrated into primary health-care services in the King Sabata Dalindyebo sub-district authority, and provides several advantages over other CHW programs, including a strong emphasis on care in households and the community rather than at primary care clinics, a total 6-week standardized training both in the classroom and the field, meticulous record-keeping of patient follow-ups, daily in-the-field support and supervision visits by supervisors ensuring accountability and the recruitment of positive-deviant mothers [9].

\section{Comparison group}

The Philani Mentor Mother program is not active in this area. Mothers and children in the comparison group have access to free primary health care at clinics and free maternity and child healthcare (up to 6 years) at government hospitals, which includes HIV care.

\section{Sample}

All pregnant women attending antenatal care during the study period and who agreed to participate were recruited by trained interviewers stationed at each of the four clinics listed above, during the recruitment period. Women living in the areas covered by the four clinics who presented to Zithulele Hospital around the time of delivery, but who were not previously recruited, were also recruited into the study. Participants who were deaf, mute or with significant psychiatric issues at initial contact were excluded. All women signed an informed consent form. In addition, those under the age of $18 \mathrm{had}$ a parent or guardian sign consent.

Figure 2 depicts the participant flow chart. Of the 1490 mothers approached at antenatal clinics and the 


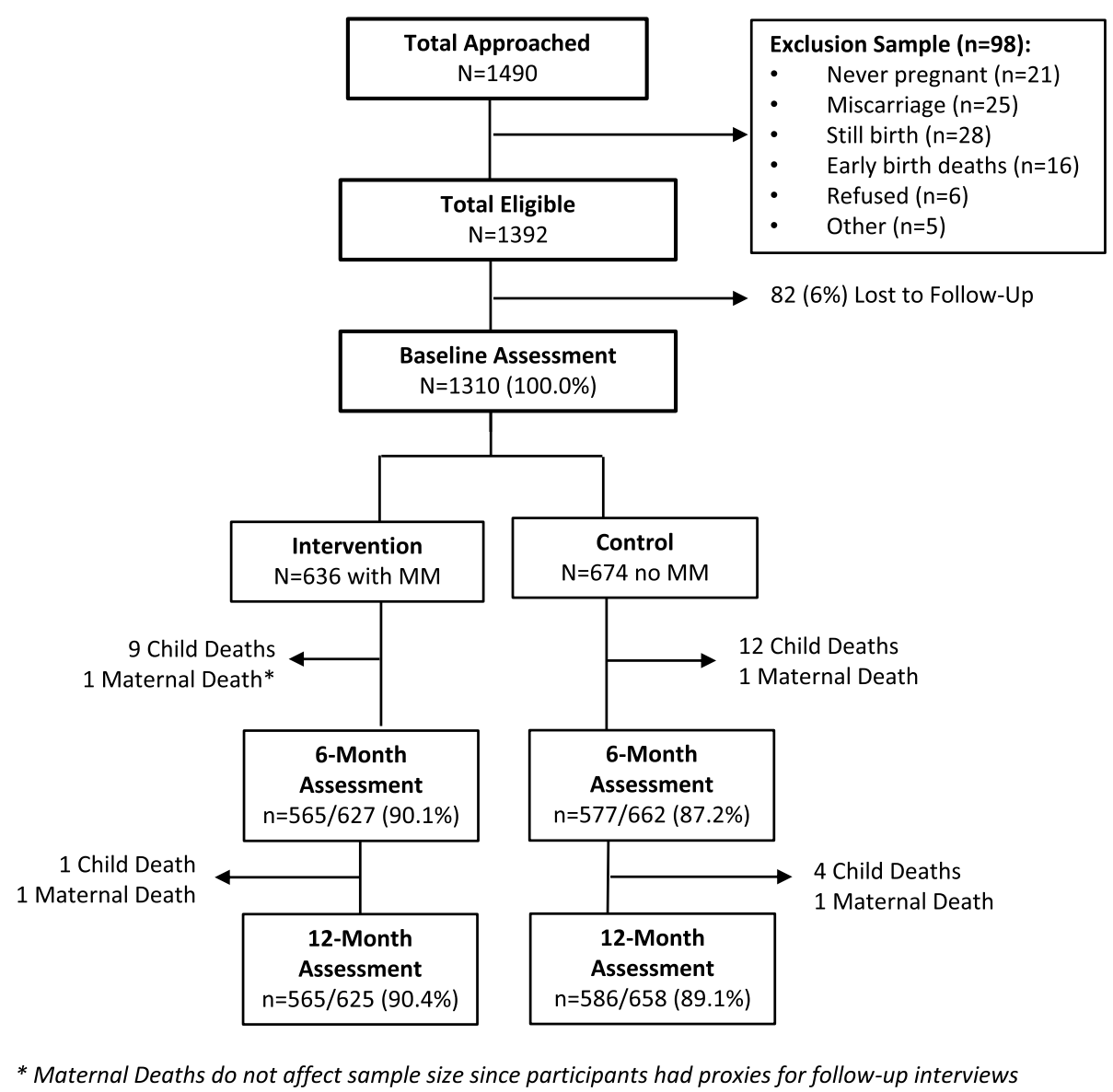

Fig. 2 Participant flow chart - by intervention (Thezi-Mapuzi) and comparison (Luthubeni-Wilo) groups

hospital, 180 women were not eligible due: no pregnancy $(n=21)$, miscarriages and intrauterine deaths $(n=53)$, early birth deaths $(n=13)$, refusal at baseline interview or other reasons $(n=11)$, and not completing the baseline interview $(n=82)$. A total of 1310 women were recruited into the study, stratified by location of clinic: (1) Mapuzi and Thezi (Intervention group; $n=636$ ); or (2) Wilo and Luthubeni (Comparison group; $n=674$ ). Baseline assessments were performed soon after the birth of the baby (median, 2 days) and at 6 -months postbirth (median, 180 days). In the analysis, babies who died by 6 -months $(n=21)$, twins or triplets $(n=17)$, and HIV-seropositive children $(n=3)$ were excluded. There were two maternal deaths by 6 months. Although child deaths did affect the overall study sample, maternal deaths did not, as long as there was a proxy for the mother's interview (i.e. caregiver like a grandmother) who could complete the assessment.

\section{Measures}

\section{Demographic characteristics}

Background characteristics collected included maternal age, highest education level achieved (years), current employment or learner status, and the presence of a live-in partner or husband. Economic resources were identified as monthly income ( 2000 South African Rand [ZAR]), receipt of the child support grant, access to electricity and safe water, and the number of adults and children that live in the household.

\section{Alcohol use}

Mothers were asked if they ever used alcohol before pregnancy, and if they continued to use alcohol after discovering they were pregnant.

\section{Maternal health}

Maternal antenatal cards detailed the medical care the mother received before pregnancy and the number of antenatal visits she attended. We collected previous pregnancy history including poor outcomes and the number of live births.

\section{Maternal mental health}

Depressive symptoms were measured using the Edinburgh Postnatal Depression Scale (EPDS). The EPDS is a 10-item scale with four Likert-type responses 
for each item, with mothers self-reports indicating possible depressed mood with scores $>13$ and probable clinical depression $\geq 18$ that has been extensively used in South Africa [24, 28-30] and has been found to "reliably and validly measure perinatal depression symptom severity or screen for probable postnatal depression in African countries" (29, p1).

\section{HIV status and adherence to PMTCT}

HIV testing during pregnancy was confirmed either by self-report or by the mother's antenatal card at baseline. Mother's HIV status, receipt of ARVs before and during pregnancy, and disclosure of HIV status were also recorded.

\section{Paternal characteristics}

At baseline, data collectors record if the child lives with the father, and the father's HIV status and substance use.

\section{Breastfeeding}

current breastfeeding at the birth interview was recorded and how soon the infant was put to the breast. At the 6months assessment, mothers self-reported whether they were exclusively breastfeeding for three and 6 months. If a mother was not exclusively breastfeeding, data collectors asked whether and when the mother started using formula, and whether she was mixing formula with baby porridge.

\section{Child outcomes}

\section{Birth outcomes}

Birthplace of the child was either at the hospital, clinic, or on the way to the hospital/clinic versus at home. Low birth-weight was defined as any infant that weighed less than $2500 \mathrm{~g}$ at the time of birth. Finally, Apgar scores were recorded at birth at $5 \mathrm{~min}$, ranging from 1 to 10 using information from the government Road to Health Card (RtHC), which is a health record kept by the mother.

\section{Growth measures}

Trained and certified interviewers weighed children (kilograms) and measured their length (centimeters) using a measuring mat at birth and 6-months. Birth weight $(\mathrm{g} / \mathrm{kg})$ was also recorded from the RtHC. Infant anthropometric data was then converted to z-scores based on the World Health Organization's (W.H.O) ageadjusted norms [31]. A z-score below -2 standard deviation (SD) was considered a serious growth deficit: < - 2 for height-for-age z-scores (HAZ) was considered stunted, $<-2$ for weight-for-age $\mathrm{z}$ scores (WAZ) was considered underweight, and $<-2$ for weight-for-height $\mathrm{z}$ scores (WHZ) were considered wasted. Growth scores of $>5 \mathrm{SD}$ or $<-5 \mathrm{SD}$ may have represented measurement errors and were replaced by 5 or -5 in order to reduce the effect of outliers in our analyses (i.e. HAZ $[n=21,0.6 \%]$, WAZ $[n=20,0.6 \%]$, and WHZ $[n=123$, $3.5 \%])$.

\section{Immunizations and vitamin a}

Data collectors asked the mothers what immunizations the child had received up to and including 6-months (plus Vitamin A) and confirmed these answers with the child's RtHC.

\section{Child illnesses}

Mothers were asked at the 6-months assessment if the child had experienced any child illness in the past 2 weeks including diarrhea, vomiting, cough, shortness of breath, fever, and/or runny nose. Mothers were asked if the mother has taken the child to the hospital, clinic, traditional healer, private doctor, or private pharmacy in the past 3 months.

\section{Child development}

WHO gross motor developmental milestones were measured at 6-months. The presence or absence of the following motor skills were assessed: (1) sitting without support; (2) standing with support; (3) hands-and-knees crawling; (4) walking with assistance; and (5) standing alone [32]. Depending on the child's age (age unit: months), a child was determined to be either on target or behind target based on the assessment of the trained interviewer.

\section{PMTCT Cascade}

Among the mothers living with HIV (MLH), the PMTC $\mathrm{T}$ cascade focused on six tasks: (1) receipt of antiretroviral (ARVs) before the birth of the baby; (2) nevirapine (NVP) administered to the infant after delivery; (3) continuation of Anti-retroviral Therapy (ART) for mother post-delivery; (4) infant received HIV PCR testing; (5) maintenance of a single feeding method (i.e. exclusive breastfeeding for 3 months); and (6) the infant received co-trimoxazole by the 6 -months assessment.

\section{Data analysis}

The key baseline demographics and maternal characteristics were compared between intervention and comparison groups, using the Student's $t$-test or Mann-Whitney $\mathrm{U}$ test for continuous variables, and the chi-square $\left(\chi^{2}\right)$ test or Fisher's exact test for categorical variables. We also examined participants who were lost to follow-up $(11 \% ; n=147)$, by comparing their baseline characteristics to mothers who were retained at 6-months assessment $(n=1142 / 1310)$ stratified by intervention and comparison groups. 
Our primary analysis compared the distribution of maternal and child outcomes by intervention and comparison groups at 6-months using $t$-test and $\chi^{2}$ test for continuous and categorical outcomes, respectively. Among MLH, we compared additional tasks in the PMTCT cascade between intervention and comparison groups using $\chi^{2}$ test.

Longitudinal mixed-effects models were used to assess the intervention effect for maternal and child outcomes that were measured over time. In particular, we applied linear mixed-effects regression models with restricted maximum likelihood estimation for continuous outcomes, and mixed-effect logistic regression models for binary outcomes. The mixed-effects models for maternal and child outcomes assessed over time, included fixed-effects for maternal HIV status, access to electricity and safe water, having total grant income above 2000 South African Rand (ZAR), intervention, time, and interaction between intervention and time. The time variable used in the longitudinal models for maternal outcomes corresponds to timepoints (baseline and 6-months) where mothers were assessed in the study, and for child outcomes refer to the actual age of children (age unit: months).

For child outcomes assessed only at 6-months, we omitted the child random-effects. Multivariate negative binomial regression models were fitted for count outcomes, where the likelihood ratio test was adapted to assess whether the negative binomial model was more appropriate than the Poisson model. For child outcomes that were assessed over time from baseline to 6-months, the effect modification was assessed by fitting interaction terms between maternal HIV status, time, and intervention in the longitudinal models. Similarly, for those child outcomes that were only measured at 6-months, this was assessed by including an interaction term between maternal HIV status and intervention in models. Further examination was carried out to assess whether maternal HIV status modifies the effect of intervention on outcomes.

All mixed-effects models accounted for repeated measures for participants by including random intercepts. Random slope for time was also assessed, and if needed, included in the models in addition to fixedeffects and random intercepts. All analyses were conducted using Stata SE software Version 15.

\section{Results}

\section{Baseline differences}

Follow-up assessments were completed by $89 \%$ of mothers and those lost to follow-up $(n=147)$ were similar to those retained $(n=1142)$ (details available from authors). Table 1 summarizes the background characteristics grouped by intervention condition. The median age of mothers was 24 years (Range, 14-50 years), with schooling for 8.8 years (SD, 2.6). About $38 \%$ of mothers $(n=493)$ were married or lived with a partner $(p \leq 0.05)$; unemployment rates were extremely high $(72.1 \%)(p=0.02)$. Mothers in the intervention group had lower total grant income $(p<0.01)$, and on average, had more antenatal visits $(p<0.01)$ and more previous pregnancies $(p<0.01)$ than those in the comparison group.

The two groups varied in the municipal services available in each area: mothers in the comparison group were about twice as likely to have electricity $(p<0.01)$ and not have safe water $(p<0.01)$ than mothers in the intervention group.

As shown in Table 1, about one-third of mothers reported living with $\operatorname{HIV}(n=391 ; 30 \%)$, and just less than half $(n=176 ; 45.1 \%)$ were on HAART before the pregnancy. Almost all MLH received ART during pregnancy $(98.7 \%)$, a majority of which were taking a single fixed dose combination (FDC) or Tenofovir/ Emtricitabine/Efavirenz (TEE) every day. MLH were much more likely to disclose their HIV status to family ( $n=278 ; 77.9 \%)$ than to their partners $(15.1 \%)$, but no differences were observed across the two groups and the average number of people disclosed to was two people $(\mathrm{SD}=0.8)$.

Regarding parental characteristics, only $15.7 \%$ of mothers lived with the father of their child and about one-third of MLH reported that they knew that the HIV status of the father of their child was positive (29.5\%); most mothers $(53.3 \%)$ were not aware of the father's HIV status.

There were no significant differences in mean WAZ, HAZ, and WHZ scores and the rate of low birth-weight infants, those stunted, underweight, and wasted across the two groups at birth, but the percentage of children wasted $(\mathrm{WHZ}<-2)$ at birth was very high at $35 \%$.

\section{Maternal outcomes at 6-months}

Table 2 compares mothers in the intervention and comparison groups on EPDS outcomes at 6-months. While findings from the adjusted analyses highlighted higher EPDS scores for mothers in the comparison group compared to the intervention group (mean difference (MD): $-0.9 ; 95 \% \mathrm{CI}:-1.7,-0.2)$, there were no differences in the prevalence of having a depressed mood (EPDS > 13) or probable clinical depression (EPDS $\geq 18$ ). No other significant differences on maternal outcomes between the intervention and control conditions were found.

\section{Child outcomes at 6-months}

As Table 3 shows, no significant differences were observed between the intervention and comparison groups 
Table 1 Baseline characteristics of the sample by Intervention $(n=636)$ and comparison $(n=674)$ groups

\begin{tabular}{|c|c|c|c|c|c|c|}
\hline & \multicolumn{2}{|l|}{$\begin{array}{l}\text { Intervention } \\
(n=636)\end{array}$} & \multicolumn{2}{|c|}{$\begin{array}{l}\text { Comparison } \\
(n=674)\end{array}$} & \multicolumn{2}{|l|}{$\begin{array}{l}\text { Total } \\
(\boldsymbol{n}=1310)\end{array}$} \\
\hline & $n$ & $(\%)$ & $n$ & $(\%)$ & $\mathrm{n}$ & (\%) \\
\hline \multicolumn{7}{|l|}{ Demographic characteristics } \\
\hline Maternal age, median [range] & $24[14,46]$ & & $23[14,50]$ & & $24[14,50]$ & \\
\hline Highest education level, mean (SD) & $8.7(2.9)$ & & $8.9(2.4)$ & & $8.8(2.6)$ & \\
\hline \multicolumn{7}{|l|}{ Employment ${ }^{* *}$} \\
\hline Employed & $48(7.6)$ & & $32(4.8)$ & & $80(6.1)$ & \\
\hline School & $123(19.4)$ & & $161(24.0)$ & & $284(21.8)$ & \\
\hline Unemployed & $464(73.1)$ & & $478(71.2)$ & & $942(72.1)$ & \\
\hline Married or lives with partner ${ }^{*}$ & $257(40.4)$ & & $236(35.1)$ & & $493(37.7)$ & \\
\hline Total grant income (> 2000 Rand) ${ }^{* * *}$ & $177(28.6)$ & & $247(37.9)$ & & $424(33.4)$ & \\
\hline Total child support grant & $577(92.1)$ & & $588(93.3)$ & & $1145(92.7)$ & \\
\hline Access to electricity ${ }^{* * *}$ & $272(42.8)$ & & $553(82.1)$ & & $825(63.0)$ & \\
\hline Access to safe water ${ }^{* * a_{a}}$ & $607(95.4)$ & & $264(39.2)$ & & $871(66.5)$ & \\
\hline Number of adults in household, mean (SD) & $3.4(1.9)$ & & $3.6(2.0)$ & & $3.5(2.0)$ & \\
\hline Number of children in household, mean (SD) & $4.0(1.9)$ & & $4.1(1.9)$ & & $4.1(1.9)$ & \\
\hline \multicolumn{7}{|l|}{ Alcohol } \\
\hline Use alcohol during pregnancy & $48(7.6)$ & & $42(6.2)$ & & $90(6.9)$ & \\
\hline Use alcohol before pregnancy & $36(5.7)$ & & $46(6.8)$ & & $82(6.3)$ & \\
\hline Continued to use alcohol after pregnancy discovery & $2(18.2)$ & & $6(37.5)$ & & $8(29.6)$ & \\
\hline \multicolumn{7}{|l|}{ Maternal and Mental health } \\
\hline Antenatal care & $635(99.8)$ & & $672(99.7)$ & & $1307(99.8)$ & \\
\hline Total antenatal visits, mean (SD) & $4.3(1.6)$ & & $3.9(1.7)$ & & $4.1(1.7)$ & \\
\hline Total previous pregnancies, mean (SD) ${ }^{* * *}$ & $1.5(1.6)$ & & $1.3(1.5)$ & & $1.4(1.6)$ & \\
\hline Number of live births, mean (SD) & $2.1(1.4)$ & & $2.0(1.4)$ & & $2.1(1.4)$ & \\
\hline EPDS, median [range] & $5[0-27]$ & & $5[0-30]$ & & $5[0-30]$ & \\
\hline EPDS $>13$ & $79(12.4)$ & & $86(12.8)$ & & $165(12.6)$ & \\
\hline EPDS $\geq 18$ & $26(4.1)$ & & $31(4.6)$ & & $57(4.4)$ & \\
\hline \multicolumn{7}{|l|}{ HIV and Reproductive Health Behavior } \\
\hline Tested for HIV during pregnancy & $568(89.6)$ & & $604(89.9)$ & & $1172(89.5)$ & \\
\hline Mothers living with HIV & $187(29.6)$ & & $204(30.4)$ & & $391(30.0)$ & \\
\hline Ever receipt ARVs & $183(97.9)$ & & $202(99.5)$ & & $385(98.7)$ & \\
\hline ARVs before pregnancy & $90(48.1)$ & & $86(42.4)$ & & $176(45.1)$ & \\
\hline ARVs currently (Single pink pill-FDC or TEE) & $172(94.0)$ & & $194(96.5)$ & & $366(95.3)$ & \\
\hline Disclosed HIV status & $173(92.5)$ & & $184(90.6)$ & & $357(91.5)$ & \\
\hline Husband/boyfriend/partner & $28(16.2)$ & & $26(14.1)$ & & $54(15.1)$ & \\
\hline Family (Mother/Sister/Mother-in-law, Other) & $137(79.2)$ & & $141(76.6)$ & & $278(77.9)$ & \\
\hline Other (Friend/Mentor-mother/CHW/Neighbor) & $8(4.6)$ & & $17(9.2)$ & & $25(7.0)$ & \\
\hline Number of people disclosed to, mean (SD) & $1.7(0.8)$ & & $1.8(0.9)$ & & $1.8(0.8)$ & \\
\hline \multicolumn{7}{|l|}{ Paternal characteristics } \\
\hline Child lives with father & $108(17.0)$ & & $98(14.5)$ & & $206(15.7)$ & \\
\hline Father alcohol use & 319 (51.9) & & $346(54.7)$ & & $665(53.3)$ & \\
\hline Father tobacco use & $188(29.8)$ & & $197(29.8)$ & & $385(29.8)$ & \\
\hline Father drug use & $32(5.2)$ & & $25(3.9)$ & & $57(4.5)$ & \\
\hline
\end{tabular}


Table 1 Baseline characteristics of the sample by Intervention $(n=636)$ and comparison $(n=674)$ groups (Continued)

\begin{tabular}{|c|c|c|c|c|c|c|}
\hline & \multicolumn{2}{|c|}{$\begin{array}{l}\text { Intervention } \\
(\mathrm{n}=636)\end{array}$} & \multicolumn{2}{|c|}{$\begin{array}{l}\text { Comparison } \\
(n=674)\end{array}$} & \multicolumn{2}{|l|}{$\begin{array}{l}\text { Total } \\
(\boldsymbol{n}=1310)\end{array}$} \\
\hline & $\mathrm{n}$ & (\%) & $n$ & (\%) & $n$ & (\%) \\
\hline Father living with HIV+ & $57(30.5)$ & & $58(28.6)$ & & $115(29.5)$ & \\
\hline \multicolumn{7}{|l|}{ Breastfeeding } \\
\hline Breastfeeding at baseline interview & $601(94.5)$ & & $644(95.6)$ & & $1245(95.0)$ & \\
\hline Breastfeed within $1 \mathrm{~h}$ of birth & $546(85.8)$ & & $556(82.5)$ & & $1102(84.1)$ & \\
\hline \multicolumn{7}{|l|}{ Child outcomes at birth } \\
\hline Birth in hospital ${ }^{* * *} \mathrm{~b}$ & $591(92.9)$ & & $649(96.3)$ & & $1240(94.7)$ & \\
\hline LBW (less than $2500 \mathrm{~g}$ ) & $65(10.5)$ & & $73(11.2)$ & & $138(10.9)$ & \\
\hline WAZ, mean (SD) & $-0.6(1.1)$ & & $-0.6(1.1)$ & & $-0.6(1.1)$ & \\
\hline Underweight (WAZ <-2 SD) & $57(9.2)$ & & $63(9.7)$ & & $120(9.5)$ & \\
\hline HAZ, mean (SD) & $0.2(1.5)$ & & $0.2(1.5)$ & & $0.2(1.5)$ & \\
\hline Stunted $(H A Z<-2$ SD) & $41(6.5)$ & & $48(7.2)$ & & $89(6.8)$ & \\
\hline WHZ, mean (SD) & $-1.8(2.3)$ & & $-1.6(2.2)$ & & $-1.7(2.2)$ & \\
\hline Wasting (WHZ <-2 SD) & $220(37.2)$ & & $213(33.5)$ & & $433(35.3)$ & \\
\hline Apgar Score at 5 min, mean (SD) & $10.0(0.7)$ & & $9.9(0.8)$ & & $10.0(0.8)$ & \\
\hline Apgar Score at 5 min (7 and above) & $588(99.5)$ & & $641(98.8)$ & & $1229(99.1)$ & \\
\hline
\end{tabular}

${ }^{*} p<0.1 ;{ }^{* *} p<0.05 ;{ }^{* * *} p<0.01$

a Safe water includes rainwater tank, communal tap running water, communal tap hand pump, hospital tap, running water tap on land, and non-safe water consists of river and well; ${ }^{b}$ Hospital/clinic or on the way to hospital vs. Home

Abbreviations: EPDS Edinburgh Postnatal Depression Scale (EPDS). LBW Low birth weight (LBW); WAZ Weight-for-age z-score (WAZ). HAZ Length/height-for-age z-score (HAZ)

in the adjusted analysis of the growth measures of HAZ and WAZ. However, the intervention group had higher mean for WHZ (MD: 0.3; 95\% CI: 0.1, 0.6), and lower odds of wasting (WHZ<-2SD) (OR: 0.5; 95\% CI: 0.3, $0.9)$ than the comparison group, as well as a trend toward a lower odds for being underweight $\left(\mathrm{WAZ}_{<-2)}\right.$ (OR: 0.4; 95\% CI: 0.1, $1.0 ; p<0.01$ ).

Intervention mothers had higher odds of exclusive breastfeeding for 6 months (OR: 1.8; 95\% CI: 1.1, 2.9) and lower odds of mixing formula with baby porridge (OR: $0.4 ; 95 \%$ CI: $0.2,0.8$ ). In addition, the odds of experiencing vomiting, cough and a runny nose in children of the intervention group were lower compared to children in the comparison group. The incident rate ratio for symptoms of common childhood illnesses was also lower for the intervention group (IRR: 0.8 ; 95\% CI: $0.7,0.9 ; p<0.05$ ).

Children in the intervention group had significantly lower odds of consulting with a traditional healer (OR: 0.2 ; $95 \% \mathrm{CI}: 0.1,0.8)$ and a private pharmacy (OR: 0.2 ; $95 \%$ CI: $0.1,0.4)$ than children in the comparison group. No significant differences were observed between the

Table 2 Maternal outcomes at 6-months grouped by intervention and comparison groups

\begin{tabular}{|c|c|c|c|c|c|c|}
\hline \multirow[b]{2}{*}{ Depression } & \multicolumn{2}{|c|}{$\begin{array}{l}\text { Intervention } \\
(\boldsymbol{n}=565)\end{array}$} & \multicolumn{2}{|c|}{$\begin{array}{l}\text { Comparison } \\
(\boldsymbol{n}=577)\end{array}$} & \multicolumn{2}{|c|}{$\begin{array}{l}\text { Estimated Mean Difference } \\
\text { Intervention vs. Comparison }\end{array}$} \\
\hline & Mean & SD & Mean & SD & Difference $^{a}$ & $95 \% \mathrm{Cl}$ \\
\hline EPDS score ${ }^{* *}$ & 4.5 & 5.0 & 5.3 & 5.4 & $-0.9^{c, d,+\dagger}$ & $(-1.7,-0.2)$ \\
\hline \multirow[t]{2}{*}{ Median [range] ${ }^{* *}$} & \multicolumn{2}{|l|}{3 [0-33] } & \multicolumn{2}{|c|}{$4[0-26]$} & & \\
\hline & & & & & \multicolumn{2}{|c|}{$\begin{array}{l}\text { Estimated Odds Ratio } \\
\text { Intervention vs. Comparison }\end{array}$} \\
\hline Depression & $\mathrm{n}$ & $\%$ & $\mathrm{n}$ & $\%$ & $O R^{b}$ & $95 \% \mathrm{Cl}$ \\
\hline EPDS score $>13^{* *}$ & 30 & 6.3 & 47 & 9.9 & $0.5^{c, e}$ & $(0.3,1.1)$ \\
\hline EPDS score $\geq 18$ & 14 & 2.9 & 18 & 3.8 & $0.6^{c, e}$ & $(0.2,1.8)$ \\
\hline
\end{tabular}

Multivariate models controlled for: maternal HIV status, access to electricity and safe water, and grant income above 2000 ZAR

${ }^{*} p$-value $<0.1{ }^{\prime * *}$-value $<0.05$, ( $t$-tests or $x^{2}$ tests). ${ }^{\dagger} p$-value $<0.1,{ }^{+\dagger} p$-value $<0.05$, for regression analyses

${ }^{a}$ Mixed-effects linear regression for continuous outcomes. ${ }^{b}$ Mixed-effects logistic regression for binary outcomes

c Random-intercept for mother

${ }^{d}$ Random-slope for time using unstructured covariance

e Random-slope for time using identity covariance structure 
Table 3 Child outcomes at 6-months grouped by intervention and comparison groups

\begin{tabular}{|c|c|c|c|c|c|c|}
\hline & \multicolumn{2}{|c|}{$\begin{array}{l}\text { Intervention } \\
(\mathrm{n}=565)\end{array}$} & \multicolumn{2}{|c|}{$\begin{array}{l}\text { Comparison } \\
(\boldsymbol{n}=574)\end{array}$} & \multicolumn{2}{|c|}{$\begin{array}{l}\text { Estimated Mean Difference } \\
\text { Intervention vs. Comparison }\end{array}$} \\
\hline & Mean & SD & Mean & SD & Difference $^{a}$ & $95 \% \mathrm{Cl}$ \\
\hline \multicolumn{7}{|l|}{ Growth measures } \\
\hline Height-for-age Z-score (HAZ) & 0.5 & 1.6 & 0.7 & 1.6 & $-0.2^{e, f}$ & $(-0.4,0.1)$ \\
\hline Weight-for-age Z score (WAZ) & 0.4 & 1.3 & 0.3 & 1.2 & $0.1^{e, f}$ & $(-0.1,0.3)$ \\
\hline \multirow[t]{3}{*}{ Weight-for-height Z-score (WHZ) ${ }^{* * *}$} & 0.3 & 1.5 & -0.0 & 1.6 & $0.3^{e, f+t+}$ & $(0.1-0.6)$ \\
\hline & & & & & \multicolumn{2}{|c|}{$\begin{array}{l}\text { Estimated Odds Ratio } \\
\text { Intervention vs. Comparison }\end{array}$} \\
\hline & $\mathrm{n}$ & $\%$ & $n$ & $\%$ & $O R^{b}$ & $95 \% \mathrm{Cl}$ \\
\hline \multicolumn{7}{|l|}{ Growth measures } \\
\hline Stunted (HAZ <-2 SD) & 33 & 5.9 & 23 & 4.1 & $1.6^{\mathrm{e}, \mathrm{f}}$ & $(0.6,3.9)$ \\
\hline Underweight (WAZ <-2 SD) & 13 & 2.3 & 22 & 3.9 & $0.4^{\mathrm{e}}$ & $(0.1,1.0)$ \\
\hline Wasting $(\mathrm{WHZ}<-2 \mathrm{SD})^{* * *}$ & 27 & 4.8 & 56 & 9.4 & $0.5^{\dagger+}$ & $(0.3,0.9)$ \\
\hline \multicolumn{7}{|l|}{ Breastfeeding } \\
\hline \multirow[t]{3}{*}{ Currently breastfeeding } & 274 & 48.5 & 301 & 52.4 & $0.5^{\mathrm{e}, \mathrm{g}}$ & $(0.1,5.4)$ \\
\hline & & & & & \multicolumn{2}{|c|}{$\begin{array}{l}\text { Estimated Odds Ratio } \\
\text { Intervention vs. Comparison }\end{array}$} \\
\hline & $\mathrm{n}$ & $\%$ & $n$ & $\%$ & $\mathrm{OR}^{c}$ & $95 \% \mathrm{Cl}$ \\
\hline \multicolumn{7}{|l|}{ Breastfeeding } \\
\hline Exclusive Breastfeeding for 3 months & 349 & 61.8 & 352 & 61.3 & 1.6 & $(0.8,3.3)$ \\
\hline Exclusive Breastfeeding for 6 months & 177 & 31.3 & 156 & 27.2 & $1.8^{+\dagger}$ & $(1.1,2.9)$ \\
\hline If not breastfeeding exclusively, started mixing formula with Nestum/Baby porridge 38 & & 80.3 & 447 & 88.3 & $0.4^{+\dagger}$ & $(0.2,0.8)$ \\
\hline Immunizations current ${ }^{*}$ & 302 & 57.5 & 280 & 52.0 & 1.1 & $(0.8,1.6)$ \\
\hline Vitamin $\mathrm{A}$ has been given & 140 & 26.7 & 139 & 25.8 & 1.3 & $(0.8,2.0)$ \\
\hline \multicolumn{7}{|l|}{ Child illness during the past 2 weeks } \\
\hline Diarrhoea & 136 & 24.1 & 130 & 22.7 & 1.3 & $(0.9,1.9)$ \\
\hline Vomiting $^{* *}$ & 49 & 8.7 & 78 & 13.4 & $0.5^{\dagger+}$ & $(0.3,0.9)$ \\
\hline Cough & 250 & 44.3 & 279 & 48.6 & $0.6^{+\dagger}$ & $(0.4,0.8)$ \\
\hline Shortness of breath & 95 & 16.8 & 115 & 20.0 & 0.8 & $(0.5,1.2)$ \\
\hline Fever & 157 & 27.8 & 188 & 32.8 & 0.8 & $(0.6,1.1)$ \\
\hline Runny nose ${ }^{* *}$ & 143 & 25.3 & 185 & 32.2 & $0.7^{+\dagger}$ & $(0.5,0.9)$ \\
\hline \multicolumn{7}{|l|}{ Medical Visits (past 3 months) } \\
\hline Hospital visit ${ }^{* *}$ & 24 & 4.3 & 43 & 7.5 & $0.5^{+}$ & $(0.3,1.1)$ \\
\hline Clinic for illness & 300 & 53.1 & 313 & 54.5 & 0.8 & $(0.6,1.2)$ \\
\hline Consulted with traditional healer ${ }^{* * *}$ & 6 & 1.1 & 24 & 4.2 & $0.2^{+\dagger}$ & $(0.1,0.8)$ \\
\hline Consulted with private doctor ${ }^{*}$ & 29 & 5.1 & 46 & 8.0 & 0.6 & $(0.3,1.2)$ \\
\hline Consulted with a private pharmacy ${ }^{* * *}$ & 29 & 5.1 & 79 & 13.8 & $0.2^{+\dagger}$ & $(0.1,0.4)$ \\
\hline \multicolumn{7}{|l|}{ WHO Development } \\
\hline \multirow[t]{3}{*}{ On/Ahead target vs Behind target } & 399 & 93.0 & 415 & 91.2 & 1.3 & $(0.7,2.6)$ \\
\hline & & & & & \multicolumn{2}{|c|}{$\begin{array}{l}\text { Estimated Incident Rate Ratio } \\
\text { Intervention vs. Comparison }\end{array}$} \\
\hline & $\mathrm{n}$ & $\%$ & $\mathrm{n}$ & $\%$ & $\operatorname{IRR}^{\mathrm{d}}$ & $95 \% \mathrm{Cl}$ \\
\hline \multicolumn{7}{|l|}{ Total Count of Symptoms during the past 2 weeks } \\
\hline 0 & 190 & 33.6 & 173 & 30.1 & $0.8^{+\dagger}$ & $(0.7,0.9)$ \\
\hline 1 & 137 & 24.3 & 128 & 22.3 & & \\
\hline
\end{tabular}


Table 3 Child outcomes at 6-months grouped by intervention and comparison groups (Continued)

\begin{tabular}{llllll}
\hline & \multicolumn{3}{l}{$\begin{array}{l}\text { Intervention } \\
(\mathrm{n}=565)\end{array}$} & $\begin{array}{l}\text { Comparison } \\
(\boldsymbol{n}=574)\end{array}$ & $\begin{array}{l}\text { Estimated Mean Difference } \\
\text { Intervention vs. Comparison }\end{array}$ \\
\hline 2 & 106 & 18.8 & 104 & 18.1 \\
3 & 74 & 13.1 & 81 & 14.1 \\
4 & 34 & 6.0 & 53 & 9.2 \\
5 & 21 & 3.7 & 26 & 4.5 \\
6 & 3 & 0.5 & 9 & 1.6 \\
\hline
\end{tabular}

Multivariate regression models controlled for: maternal HIV status, access to electricity and safe water, and having total grant income above 2000 ZAR

${ }^{*} \mathrm{p}$-value $<0.1,{ }^{* * *} \mathrm{p}$-value $<0.05,{ }^{* * *} \mathrm{p}$-value $<0.001$ (t-tests or $\mathrm{x}^{\mathrm{b}}$ tests); ${ }^{\dagger} \mathrm{p}$-value $<0.1,{ }^{+\dagger} \mathrm{p}$-value $<0.05,{ }^{++\dagger} \mathrm{p}$-value $<0.001$ for regression analyses

${ }^{\mathrm{a}}$ Mixed-effects linear regression for continuous outcomes; ${ }^{\mathrm{b}}$ Mixed-effects logistic regression for binary outcomes; ${ }^{\mathrm{c}}$ Multivariate logistic regression for binary

outcomes; ${ }^{\mathrm{d}}$ Multivariate negative binomial regression for count outcomes

${ }^{\text {e }}$ Random-intercept for child

${ }^{\mathrm{f}}$ Random-slope for time using unstructured covariance

${ }^{g}$ Random-slope for time using identity covariance structure

two groups in terms of having up-to-date immunizations, receiving vitamin $\mathrm{A}, \mathrm{WHO}$ developmental milestones, clinic visits for illness, or consulting with a private doctor in the past 3 months, but there was a trend towards fewer hospital visits for illness in the intervention group (OR: 0.5; 95\% CI 0.3, 1.1).

Maternal HIV status tended to modify the effect of the intervention on exclusive breastfeeding for 6 months ( $p=0.09$; likelihood ratio test). In particular, the effect of the intervention was strong for mothers who were not HIV infected (OR: 2.1; 95\% CI: 1.2, 3.4), indicating about a two-fold increase in the odds of exclusive breastfeeding compared to the non-MLH in the comparison group (see Table 4). There was no intervention effect observed on exclusive breastfeeding at 6 months for MLH. Maternal HIV status did not modify the effect of the intervention on any of the other maternal or child outcomes.

\section{Interventions to protect HIV-exposed infants}

MLH completed PMTCT tasks and other interventions to protect their HIV-exposed infants (Fig. 3) at similar rates with high compliance in terms of receiving ARVs before or during pregnancy $(n=382$; 98.0\%); administering infants Nevirapine (NVP) syrup soon after birth $(n=$ 370 ; $94.9 \%)$; adhering to $\mathrm{ARVs}$ at 6 -months $(n=282$; 94.6\%) and completing infant PCR testing $(n=278$; 93.6\%). However, MLH in the intervention group were much more likely to be giving infants co-trimoxazole at 6-months $(37.7 \%$ vs $17.1 \% ; p<0.01)$ compared to MLH in the comparison group.

Table 4 Effect modification by maternal HIV status for exclusively breastfeeding for 6 months

\begin{tabular}{|c|c|c|c|c|}
\hline \multirow{2}{*}{$\begin{array}{l}\text { Exclusively breastfeeding for } 6 \\
\text { months }\end{array}$} & \multicolumn{2}{|c|}{ MLH } & \multicolumn{2}{|c|}{ Non-MLH } \\
\hline & $\mathrm{OR}$ & $95 \% \mathrm{Cl}$ & $\mathrm{OR}$ & $95 \% \mathrm{Cl}$ \\
\hline Intervention vs. comparison group & 0.9 & $(0.4,2.3)$ & 2.1 & $(1.2,3.4)$ \\
\hline
\end{tabular}

\section{Discussion}

Home-visits by Philani CHWs had limited, yet important, health effects on mothers and their children. Maternal depressive symptoms were fewer and child health care behaviours were enhanced. Antenatal visits were higher, and exclusive breastfeeding rates at 6-months were higher (especially amongst HIV negative women) and mothers were less likely take their children to a traditional healer. MLH in the intervention group were more likely to be giving their children co-trimoxazole at 6-months. Children tended to have fewer hospital visits, fewer symptoms of illness in the preceding two weeks, were marginally less likely to be underweight-for-age and were significantly less likely to be wasted in the intervention group than the comparison group.

Many of these impacts can be attributed to specific interventions by CHWs: higher antenatal care attendance, higher exclusive breastfeeding rates and lower traditional healer visits are likely to be linked to strong repeated messages given by $\mathrm{CHW}$ during home visits. Other effects may be more indirect - lower average depression scores may be due to the benefits of peer support, while nutritional and health benefits may be due to better breastfeeding practices by women who were regularly visited and supported in this by $\mathrm{CHW}$.

Mothers in the intervention condition had lower average depressed mood scores, but the clinical impact of this is difficult to quantify, as mean EPDS scores were well below 13. Most studies of maternal depression (even those using a screening tool) find rates of at least $20 \%[33,34]$. The impact of CHW on depression is consistent with previous findings in both peri-urban $[35,36]$ and rural settings (L Stansert Katzen et al. 2019 - in submission). This may be attributed to the emotional and practical support provided by $\mathrm{CHW}$ during homevisits and this is an important area for future research. Additionally, it is notable that this study is the second from the Eastern Cape where overall EPDS scores are much lower when compared to urban settings [37]. The 


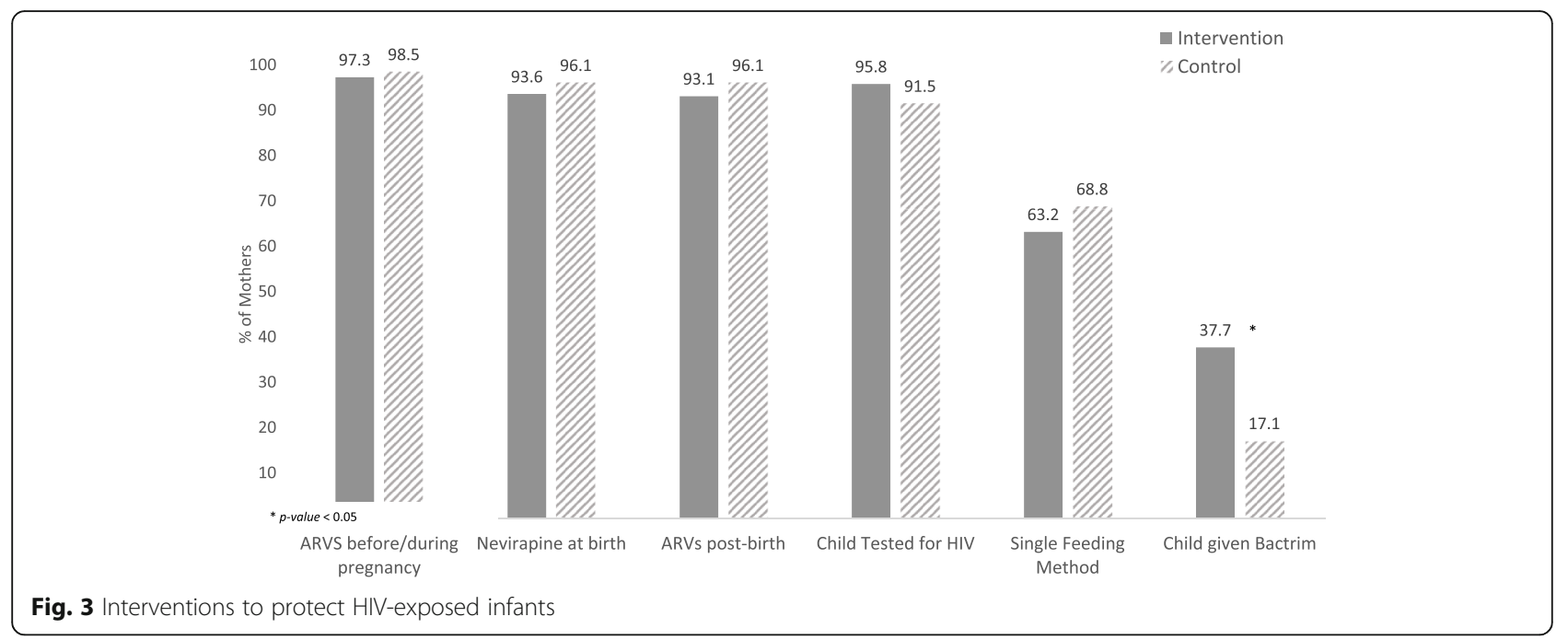

lower levels of depression may be attributed to stronger family ties and community resources, despite poverty and inadequate government services, and a healthier living environment as compared to peri-urban settlements. More research is required to elucidate this.

Home visiting resulted in fewer underweight infants as well as wasted infants over time. Other studies have shown that maternal characteristics such as mother's antenatal care and place of delivery were predictive of underweight, stunted and wasted infants. However, these data were cross-sectional and not longitudinal [20].

As expected, our findings of wasting is similar to a meta-analyses that found wasting is more prevalent in rural areas than compared to urban settings [38] and are more prevalent in households with low SES compared to higher SES [39]. However, the percentage of children who are wasted at birth (35\%) is striking, even as this improves to $4.6 \%$ (intervention) and 9.4\% (control) by 6 months. Additionally, mothers in the intervention group attended significantly more antenatal visits during pregnancy, which is linked to better pregnancy outcomes [40] and in line with WHO Antenatal Guidelines that promote additional antenatal visits. Intervention group mothers also engaged in healthier infant feeding behaviours. The appropriate feeding of infants is seen as critical to their health, growth and well-being [41], and mothers who received the intervention were more likely to exclusively breastfeed their infants for 6 months, and were less likely to mix cereal porridge into their formula bottle if not exclusively breastfeeding - which is regarded as a potentially harmful feeding practice [42]. A key aspect of the support CHWs provide is feeding advice and it was important that there were higher levels of exclusive breastfeeding at 6 months and less mixing of porridge with formula. Breastfeeding rates were relatively high at about 61.6\% (five times higher than in peri-urban settings [43].

Finally, in terms of clinical symptoms and care behaviours, infants in the intervention group were significantly less likely to have experienced one of six symptoms of common childhood illnesses, and independently had less vomiting, coughing and coryza (runny nose) than children in the comparison group. This may be due to the health benefits of higher exclusive breastfeeding rates in the intervention group or other care behaviours imparted by $\mathrm{CHW}$ to mothers. Hospital visits, a proxy for potentially serious illnesses, were also marginally less common in the intervention group. (Most women take their children to their nearest PHC clinic when unwell, children who are very ill or do not respond to clinic treatment are referred to the district hospital. On occasion, severely ill children will be taken directly to the hospital). Mothers in the comparison group were more likely to take their children to traditional healers and to private pharmacies for health consultations. The latter is most likely due to the fact that the comparison area is significantly closer to the nearest big town which has a private pharmacy with a consulting nurse on the premises. Consulting traditional healers is common in rural villages of South Africa, and may result in children being exposed to harmful or even fatal treatments $[44,45]$. It is interesting that mothers in the comparison group were nearly five times the odds more likely to seek a traditional healer's advice or treatment than those in the intervention group. This may be attributed to CHWs themselves having trust in local government $\mathrm{PHC}$ clinics and therefore facilitating access to clinics and the district hospital for mothers in the intervention group by providing referral letters or accompanying mothers to facilities. 
The effect modification of HIV on exclusive breastfeeding at 6 months was notable: removing MLH from the analysis shifted the odds ratio of this practice from 1.8 to 2.1 for the intervention group (Table 4). We suspect that this is due to the strong ART programme at Zithulele Hospital and its clinics, where pregnant mothers are carefully counselled and encouraged to exclusively breastfeed, thereby increasing the proportion of mothers in the control area who are well counselled and therefore choose to exclusively breastfeed, diluting the measurable impact of the CHW breastfeeding counselling and support in the intervention area.

For MLH, the rate of co-trimoxazole uptake from 6 weeks after birth was significantly higher in the intervention group than in the comparison group, yet, at 37\%, was still concerningly low. This may have been due to co-trimoxazole syrup stock-outs in clinics at the time of the study or nurses may have been unaware of cotrimoxazole guidelines for HIV-exposed infants. It is however encouraging that compliance of other interventions to protect HIV-exposed infants (see Fig. 3) in both conditions was higher than $90 \%$ - even in this deeply rural area - likely an important factor undergirding the dramatic decrease in HIV incidence in children in South Africa over the past years [46].

The Cape Town randomized controlled trial evaluating the CHW program showed more substantial impacts on mothers and their babies, particularly in "Interventions to protect HIV-exposed infants", there referred to as the "PMTCT cascade" [18]. However, since the study in Cape Town was performed in 2008, the implementation of government PMTCT protocols have improved markedly in PHC clinics to close to $90 \%$ as illustrated above. The impact of CHW is therefore more difficult to quantify with baseline compliance rates so high.

\section{Limitations}

While the matching of the two arms was mostly successful, there were significant differences between the two areas in terms of access to safe drinking water and electricity. The intervention area had good access to safe municipal water, but poor access to electricity, while in the comparison area the inverse was true. It is difficult to know what the impact of this balance of municipal services was on the mothers and their babies and whether one or other area was "advantaged" by this difference, although these were corrected for in the analyses. A cluster randomized controlled trial would be more robust to avoid confounders in further evaluations. We also did not assess the intervention dosage or have access to maternal HIV testing results and had to rely on self-report.

\section{Conclusion}

This study shows limited but important effects of a $\mathrm{CHW}$ home-visiting program in a deeply rural area of South Africa. It appears that the positive impact of CHWs on health outcomes is more difficult to achieve in the rural context than in more densely populated urban and peri-urban areas [18]. This needs to be considered when implementing rural $\mathrm{CHW}$ programs and greater investments in transport and support of CHWs may be required to ensure the effectiveness of the intervention. It is important to recognise that the CHWs assessed in this study had only been established in the area for 12-18 months and that assessments of other CHW programs occurred after these programs had embedded themselves into communities over many years [18]. Nevertheless, mothers who were visited by CHWs before and for up to a 6 months after delivery exclusively breastfed for longer, attended antenatal care more often, had lower levels of depressive symptoms and higher trust in government healthcare services. Their children were also significantly less likely be wasted at 6 -months. In conclusion, $\mathrm{CHW}$ have an important role to play in the provision of PHC services in rural areas, but need to be managed in the light of the rural context and supported accordingly.

\section{Abbreviations \\ CHW: Community health workers; PHC: Primary healthcare clinics; SA: South African; NDOH: National Department of Health; NGO: Non-Governmental Organization; PMTCT: Prevention of mother-to-child HIV transmission; ZAR: South African Rand; EPDS: Edinburgh Postnatal Depression Scale; RtHC: Road-to-Health-Card; W.H.O: World Health Organization; HAZ: Height- for-age z scores; WAZ: Weight-for-age z scores; WHZ: Weight-for-height z scores; MLH: Mothers living with HIV; ARV: Antiretroviral; NVP: Nevirapine; ART: Anti-retroviral therapy; FDC: Fixed dose combination; TEE: Tenofovir/ Emtricitabine/Efavirenz}

\section{Acknowledgements}

Not applicable.

\section{Authors' contributions}

$K L R, M T, I L R$, and MJR designed the study. KLR, NM, and ILR were responsible for the preparation and implementation of the project. KLR was responsible for the overall design of the manuscript, and ED, LS, KLR, MT, MJR, EA and PHR all wrote sections of the manuscript. KLR, MT, MJR, PHR, VB, and NM provided critical revisions to the manuscript.. EA and PHR were responsible for data analytics. ILR and NM helped train community health workers. ED and VB supervised field operations and managed the acquisition of data in collaboration with LSK and KLR. All authors have read and approved the manuscript.

\section{Funding}

This study was funded by the National Institute of Mental Health (NIMH; R01MH111391), the ELMA Foundation and the Church of Sweden. None of the funders were involved in the design of the study, nor were they involved in the collection, analysis, and interpretation of data and in writing the manuscript.

\section{Availability of data and materials}

The raw datasets generated and/or analyzed during the current study are not publicly available due to the sensitivity and availability of geographic data, but anonymized data sets are available from the corresponding author on reasonable request. 


\section{Ethics approval and consent to participate}

Permission to recruit pregnant women at health facilities was granted by the Eastern Cape Department of Health through the Office of Epidemiological Research and Surveillance Management and ethics approval was granted by Health Research Ethics Committee at Stellenbosch University, N14/03/019. Informed consent had been obtained from participants. All participants signed a written informed consent form. Participants under the age of 18 had a parent or guardian sign a written informed consent form.

\section{Consent for publication}

Not applicable.

\section{Competing interests}

The authors declare that they have no competing interests.

\section{Author details}

${ }^{1}$ Institute for Life Course Health Research, Department of Global Health, Stellenbosch University, Tygerberg, South Africa. ${ }^{2}$ Zithulele Training and Research Centre, Zithulele Hospital, Ginyintsimbi Village, Eastern Cape, South Africa. ${ }^{3}$ Family Medicine Department, Walter Sisulu University, Mthatha, South Africa. ${ }^{4}$ Primary Healthcare Directorate, University of Cape Town, Cape Town, South Africa. ${ }^{5}$ Department of Psychiatry and Biobehavioral Sciences, Semel Institute, University of California, 10920 Wilshire Boulevard, Suite 350, Los Angeles, CA 90024-6521, USA. ${ }^{6}$ Philani Maternal, Child Health and Nutrition Trust, Site C, Khayelitsha, Cape Town, South Africa. ${ }^{7}$ School of Nursing and Midwifery, Queens University, Belfast, UK.

\section{Received: 11 March 2020 Accepted: 28 August 2020} Published online: 17 September 2020

\section{References}

1. Silal SP, Penn-Kekana L, Harris B, Birch S, Mclntyre D. Exploring inequalities in access to and use of maternal health services in South Africa. BMC Health Serv Res. 2012;12:120.

2. TAC. State of Provincial Healthcare System SPotlight on KwaZulu- - - Natal May 2018, (May). 2018.

3. Harris B, Goudge J, Ataguba JE, Mclntyre D, Nxumalo N, Jikwana S, et al. Inequities in access to health care in South Africa. J Public Health Policy. 2011:32(Suppl 1):S102-23.

4. Singh P, Sachs JD. 1 million community health workers in sub-Saharan Africa by 2015. Lancet. 2013;382(9889):363-5.

5. Olaniran A, Smith H, Unkels R, Bar-Zeev S, van den Broek N. Who is a community health worker? - a systematic review of definitions. Glob Health Action. 2017:10(1):1272223.

6. Strachan DL, Kallander K, Ten Asbroek AHA, Kirkwood B, Meek SR, Benton L, et al. Interventions to improve motivation and retention of community health workers delivering integrated community case management (iCCM): stakeholder perceptions and priorities. Am J Trop Med Hyg. 2012;87(5 Suppl):111-9.

7. Swider SM. Outcome effectiveness of community health workers: an integrative literature review. Public Health Nurs. 2002;19(1):11-20.

8. Austin-Evelyn K, Rabkin M, Macheka T, Mutiti A, Mwansa-Kambafwile J, Dlamini T, et al. Community health worker perspectives on a new primary health care initiative in the eastern cape of South Africa. PLoS One. 2017; 12(3):e0173863.

9. le Roux K, le Roux I, Mbewu N, Davis E. The Role of Community Health Workers in the Re-Engineering of Primary Health Care in Rural Eastern Cape. S Afr Fam Pract. 2015;57(2):116-20.

10. Siruma A, Hornby D, Srinivas $S$. An assessment of maternal health issues in two villages in the eastern cape province of South Africa. Int J Environ Res Public Health. 2014;11(9):9871-84.

11. Swartz A, Colvin CJ. It's in our veins': caring natures and material motivations of community health workers in contexts of economic marginalisation. Crit Public Health. 2015;25(2):139-52.

12. Perry HB, Zulliger R, Rogers MM. Community health workers in low-, middle, and high-income countries: an overview of their history, recent evolution, and current effectiveness. Annu Rev Public Health. 2014;35:399-421.

13. Gilmore B, McAuliffe E. Effectiveness of community health workers delivering preventive interventions for maternal and child health in lowand middle-income countries: a systematic review. BMC Public Health. 2013; 13:847.
14. Horwood C, Butler L, Barker P, Phakathi S, Haskins L, Grant M, et al. A continuous quality improvement intervention to improve the effectiveness of community health workers providing care to mothers and children: a cluster randomised controlled trial in South Africa. Hum Resour Health. 2017;15(1):39

15. Moshabela M, Sips I, Barten F. Needs assessment for home-based care and the strengthening of social support networks: the role of community care workers in rural South Africa. Glob Health Action. 2015;8:29265.

16. Brenner JL, Kabakyenga J, Kyomuhangi T, Wotton KA, Pim C, Ntaro M, et al. Can volunteer community health workers decrease child morbidity and mortality in southwestern Uganda? An impact evaluation. PLoS One. 2011; 6(12):e27997.

17. Haines A, Sanders D, Lehmann U, Rowe AK, Lawn JE, Jan S, et al. Achieving child survival goals: potential contribution of community health workers. Lancet. 2007;369(9579):2121-31.

18. le Roux I, Tomlinson M, Harwood JM, O'Connor MJ, Worthman CM, Mbewu $\mathrm{N}$, et al. Outcomes of home visits for pregnant mothers and their infants: a cluster randomized controlled trial. AIDS. 2013;27(9):1461-71.

19. Tomlinson M, Rotheram-Borus MJ, le Roux IM, Youssef MK, Nelson S, Scheffler A, et al. Thirty-Six-Month Outcomes of a Generalist Paraprofessional Perinatal Home Visiting Intervention in South Africa. Prev Sci. 2016.

20. Olusanya BO, Wirz SL, Renner JK. Prevalence, pattern and risk factors for undernutrition in early infancy using the WHO multicentre growth reference: a community-based study. Paediatr Perinat Epidemiol. 2010;24(6): 572-83.

21. Wilford A, Phakathi S, Haskins L, Jama NA, Mntambo N, Horwood C. Exploring the care provided to mothers and children by community health workers in South Africa: missed opportunities to provide comprehensive care. BMC Public Health. 2018;18(1):171.

22. Rotheram-Borus MJ, le Roux IM, Tomlinson M, Mbewu N, Comulada WS, le Roux K, et al. Philani plus (+): a Mentor mother community health worker home visiting program to improve maternal and infants' outcomes. Prev Sci. 2011;12(4):372-88

23. Rotheram-Borus MJ, Tomlinson M, le Roux IM, Harwood JM, Comulada S, O'Connor MJ, et al. A cluster randomised controlled effectiveness trial evaluating perinatal home visiting among south African mothers/infants. PLoS One. 2014;9(10):e105934.

24. Tomlinson M, Rotheram-Borus MJ, Harwood J. et al. Community health workers can improve child growth of antenatally-depressed, South African mothers: a cluster randomized controlled trial. BMC Psychiatry. 2015;15;225. https://doi.org/10.1186/s12888-015-0606-7.

25. Writer S. The richest and poorest municipalities in South Africa Businesstech co.za: BusinessTech; 2016.

26. King Sabata Dalindyebo. Wazimap. 2016 [cited February 14, 2020]. Available from: https://wazimap.co.za/profiles/municipality-EC157-king-sabatadalindyebo/.

27. Le Roux K, Akin-Olugbade O, Katzen LS, Laurenzi C, Mercer N, Tomlinson M, et al. Immunisation coverage in the rural eastern cape - are we getting the basics of primary care right? Results from a longitudinal prospective cohort study. S Afr Med J. 2016:107(1):52-5.

28. Cox JL, Holden JM, Sagovsky R. Detection of postnatal depression. Development of the 10-item Edinburgh postnatal depression scale. $\mathrm{Br} J$ Psychiatry. 1987;150:782-6.

29. Tsai AC, Scott JA, Hung KJ, Zhu JQ, Matthews LT, Psaros C, et al. Reliability and Validity of Instruments for Assessing Perinatal Depression in African Settings: Systematic Review and Meta-Analysis. PLOS ONE. 2013;8(12): e82521. https://doi.org/10.1371/journal.pone.0082521.

30. Tomlinson M, Rotheram-Borus MJ, Scheffler A, le Roux I. Antenatal depressed mood and child cognitive and physical growth at 18-months in South Africa: a cluster randomised controlled trial of home visiting by community health workers. Epidemiol Psychiatr Sci. 2018;27(6):601-10.

31. W.H.O. WHO Child Growth Standards based on length/height, weight and age. Acta Paediatr Suppl. 2006:450:76-85.

32. De Onis M. WHO motor development study: windows of achievement for six gross motor development milestones. Acta Paediatr Suppl. 2006; 450:86-95.

33. Hartley M, Tomlinson M, Greco E, Comulada WS, Stewart J, le Roux I, et al. Depressed mood in pregnancy: prevalence and correlates in two Cape Town peri-urban settlements. Reprod Health. 2011:8:9. 
34. Cooper PJ, Tomlinson M, Woolgar L, Murray M, Molteno C. Post-partum depression and the mother-infant relationship in a south African peri-urban settlement. Br J Psychiatry. 1999;175(6):554-8.

35. Tsai AC, Tomlinson M, Dewing S, le Roux IM, Harwood JM, Chopra M, et al. Antenatal depression case finding by community health workers in South Africa: feasibility of a mobile phone application. Archiv Women Ment Health. 2014;17(5):423.

36. Tomlinson M, Rotheram-Borus MJ, le Roux IM, Youssef M, Nelson SH, Scheffler A, et al. Thirty-six-month outcomes of a generalist paraprofessional perinatal home visiting intervention in South Africa on maternal health and Child health and development. Prev Sci. 2016;17(8):937-48.

37. Christodoulou J, Le Roux K, Tomlinson M, Le Roux IM, Katzen LS, RotheramBorus MJ. Perinatal maternal depression in rural South Africa: Child outcomes over the first two years. J Affect Disord. 2019;247:168-74.

38. Ozaltin E, Hill K, Subramanian SV. Association of maternal stature with offspring mortality, underweight, and stunting in low- to middle-income countries. JAMA. 2010;303(15):1507-16.

39. Finlay JE, Ozaltin $\mathrm{E}$, Canning D. The association of maternal age with infant mortality, child anthropometric failure, diarrhoea and anaemia for first births: evidence from 55 low- and middle-income countries. BMJ Open. 2011;1(2):e000226.

40. W.H.O. WHO recommendations on antenatal care for a positive pregnancy experience. World Health Organization. 2016.

41. Victora CG, Bahl R, Barros AJ, Franca GV, Horton S, Krasevec J, et al. Breastfeeding in the 21st century: epidemiology, mechanisms, and lifelong effect. Lancet. 2016:387(10017):475-90.

42. Rubertsson S. Go with the (milk) flow - infant feeding practices and premature introduction of solids in rural eastern Cape South Africa. Lund University; 2018

43. le Roux IM, Tomlinson M, Harwood JM, O'Connor MJ, Worthman CM, Mbewu N, et al. Outcomes of home visits for pregnant mothers and their infants: a cluster randomized controlled trial. AIDS. 2013;27(9):1461-71.

44. Bland RM, Rollins NC, Van den Broeck J, Coovadia HM, Child HG. The use of non-prescribed medication in the first 3 months of life in rural South Africa. Tropical Med Int Health. 2004;9(1):118-24.

45. Peltzer K, Phaswana-Mafuya N, Treger L. Use of traditional and complementary health practices in prenatal, delivery and postnatal care in the context of HIV transmission from mother to child (PMTCT) in the eastern cape, South Africa. Afr J Tradit Complement Altern Med. 2009;6(2): 155-62.

46. Barron P, Pillay Y, Doherty T, Sherman G, Jackson D, Bhardwaj S, et al. Eliminating mother-to-child HIV transmission in South Africa. Bull World Health Organ. 2013;91(1):70-4.

\section{Publisher's Note}

Springer Nature remains neutral with regard to jurisdictional claims in published maps and institutional affiliations.

Ready to submit your research? Choose BMC and benefit from:

- fast, convenient online submission

- thorough peer review by experienced researchers in your field

- rapid publication on acceptance

- support for research data, including large and complex data types

- gold Open Access which fosters wider collaboration and increased citations

- maximum visibility for your research: over $100 \mathrm{M}$ website views per year

At $\mathrm{BMC}$, research is always in progress.

Learn more biomedcentral.com/submissions 